\title{
SISTEMAS DE INOVAÇÃO E DESENVOLVIMENTO as implicações de política
}

\author{
José Eduardo Cassiolato \\ helena Maria Martins Lastres
}

\begin{abstract}
Resumo: A partir da discussão sobre uma co-evolução das idéias conceituais e analíticas a respeito do processo inovativo e da formulação de políticas nos países mais desenvolvidos, este texto argumenta que a incompreensão das particularidades do processo inovativo - e de suas conseqüências para o desenvolvimento - tem levado a equívocos que impedem avançar no sentido de propor e implementar políticas que dêem conta dos desafios e oportunidades colocados atualmente à sociedade e economia brasileiras.

Palavras-chave: Inovação. Desenvolvimento. Política industrial e tecnológica.
\end{abstract}

Abstract: Starting with a discussion about a co-evolution of conceptual and analytical ideas about the innovation process and the design of industrial and technological policies in developed countries, the paper argues that the misunderstanding of the specificities of the innovation process has led to the design and implementation of adequate policies to deal with the threats and opportunities faced by the Brazilian economy and society.

Key words: Innovation. Development. Industrial and technological politics.

$\mathrm{N}$ um período marcado pela crescente incorporação de conhecimentos nas atividades produtivas, a inovação passou a ser entendida como variável ainda mais estratégica para a competitividade de organizações e países. Estes têm enfrentado as mudanças dela decorrentes de forma diferenciada, tendo em vista suas especificidades históricas e socioeconômicas e as possibilidades permitidas pela sua inserção geopolítica. Alguns países têm obtido melhores resultados tanto em termos do aproveitamento das oportunidades apresentadas, como pela superação das dificuldades inerentes ao processo de transformação. Este trabalho argumenta que esses países conseguiram definir e implementar novas estratégias capazes de reforçar e ampliar suas políticas científicas, tecnológicas e industriais. Essas políticas realçam a mobilização dos processos de aquisição e uso de conhecimentos e de capacitações produtivas e inovativas como parte integrante fundamental de suas estratégias de desenvolvimento. Tal mobilização é estruturada a partir do conceito de "sistemas de inovação".

$\mathrm{Na}$ segunda metade dos anos 90, a palavra mágica "inovação" chegou ao Brasil, mas parece ainda não ter sido assimilada e talvez sequer bem compreendida. De fato, ela tem sido incluída na agenda das políticas industriais e tecnológicas. Porém, não se percebem resultados mais concretos das políticas implementadas, e o desempenho inovativo da economia brasileira continua modesto. $\mathrm{Na}$ maioria das vezes, o padrão de inovação que ocorre na economia brasileira ainda é defensivo e adaptativo. A exceção se encontra em segmentos da agroindústria (devido ao papel da Embrapa e às especificidades do processo de geração e difusão de inovações na agricultura), em algumas atividades historicamente percebidas como estratégicas e naquelas em que o papel do Estado foi 
fundamental na constituição de sistemas de inovação e que se mantêm sob controle nacional, como o setor de petróleo e o aeronáutico.

Este texto argumenta que a incompreensão das particularidades do processo inovativo e de suas conseqüências para o desenvolvimento tem levado a equívocos que impedem avançar no sentido de criar propostas e implementações políticas que dêem conta dos desafios e oportunidades colocados atualmente à sociedade e à economia brasileira.

O texto está organizado da seguinte maneira: o item 2 apresenta uma breve discussão da co-evolução das idéias conceituais e analíticas sobre o processo inovativo e a formulação de políticas nos países mais desenvolvidos. Esta co-evolução centra-se, por um lado, no entendimento da inovação não como um ato isolado por parte de uma empresa ou organização individual, mas sim como um processo sistêmico e interativo e, por outro lado, na reformulação das políticas voltadas à inovação a partir de tais concepções. Esse item também argumenta que a abordagem neoschumpeteriana de sistemas de inovação apresenta importantes pontos de conexão com a literatura estruturalista latino-americana produzida a partir do final dos anos 40, especialmente no âmbito da Comissão Econômica para a América Latina. O item 3 apresenta argumentos sobre a vantagem da abordagem de sistemas de inovação, tanto para tratar a realidade de países como o Brasil, mas principalmente para orientar a definição e implementação de política. O item 4 argumenta que há importantes conexões entre o enfoque neo-schumpeteriano em sistemas de inovação e o pensamento latino-americano sobre desenvolvimento. $\mathrm{O}$ item 5 apresenta as novas políticas implementadas pelos países mais avançados a partir do referencial de sistemas de inovação. O item 6 discute os principais desafios a serem superados por países em desenvolvimento para definir e colocar em prática políticas voltadas a sistemas de inovação.

\section{A CO-EVOLUÇÃO DAS IDÉIAS SOBRE INOVAÇÃO E DAS POLÍTICAS INDUSTRIAIS E TECNOLÓGICAS}

Sabe-se que até mesmo economistas que colocaram o processo de inovação no centro de suas teorias de desenvolvimento, como Joseph Schumpeter, não o estudaram em profundidade. É apenas a partir do final dos anos 60 que, através de diversos estudos empíricos houve um avanço da compreensão sobre o significado da "inovação". Até então, a inovação era vista como ocorrendo em estágios sucessivos e independentes de pesquisa básica, pesquisa aplicada, desenvolvimento, produção e difusão (visão linear da inovação). Geralmente a discussão sobre as fontes mais importantes de inovação polarizava-se entre aqueles que atribuíam maior importância ao avanço do desenvolvimento científico (science push) e os que destacavam a relevância das pressões da demanda por novas tecnologias (demand pull).

Nas décadas seguintes, ocorre uma revisão em tal conceituação: amplia-se a compreensão deste conceito. A inovação passou a ser vista não como um ato isolado, mas sim como um processo de aprendizado não-linear, cumulativo, específico da localidade e conformado institucionalmente. Essa revisão foi muito influenciada por dois grandes programas de pesquisa empírica.

O primeiro foi o Projeto SAPPHO realizado sob a coordenação de Chris Freeman no Science and Technology Policy Research - SPRU da Universidade de Sussex. Utilizando como metodologia uma metáfora da pesquisa em biologia, o projeto comparou 50 inovações que tinham obtido sucesso $^{1}$ com aquelas que não se concretizaram ${ }^{2}$. Os resultados (ROTHWELL et al., 1974) sugeriram que algumas poucas características explicavam as diferenças entre sucesso e falha. Além de registrar a importância das diferentes atividades internas à firma (produção, marketing, vendas etc.) e também enfatizar a importância do ambiente nacional, o projeto apontou como principais atributos dos casos de sucesso: as ligações com fontes externas à firma de informação científica e tecnológica - os inovadores que tinham obtido sucesso, apesar de possuir seu próprio laboratório interno de P\&D faziam uso considerável de fontes externas, enquanto os casos de insucesso eram caracterizados por falhas de comunicação com as mesmas; e a preocupação com as necessidades dos usuários e formações de redes - inovações que falharam eram caracterizadas por falta de comunicação com os usuários, ao passo que as que tinham tido sucesso caracterizaram-se por tentativas explícitas de entender as necessidades dos usuários, quase sempre através de processos cooperativos e interativos.

Enquanto o SAPPHO dirigiu a análise para a inovação, a Yale Innovation Survey - YIS realizada nos EUA concentrou-se no entendimento das estratégias das grandes empresas norte-americanas para o desenvolvimento de novos produtos e processos. Os resultados da YIS demonstraram a extrema importância, para a inovação, da acumulação de capacitações internas, fundamentais para 
que as empresas pudessem interagir com o ambiente externo. Mostraram também que a engenharia reversa era uma forma utilizada pela grande maioria das empresas norteamericanas para apropriação de conhecimentos gerados na economia como um todo.

Nesse sentido, evidenciou-se a relevância de fontes de informação externas à firma, em particular as associadas, principalmente, aos fluxos de conhecimento entre agentes produtivos da mesma cadeia de produção e, em escala reduzida, à universidade. Os resultados da YIS mostraram ainda que a freqüência e intensidade das relações de cooperação dependem significativamente de políticas públicas direta ou indiretamente voltadas para o desenvolvimento científico e tecnológico (KLEVORICK et al., 1995) e apresentam significativas diferenças por áreas científicas, setores de atividade e natureza das inovações. ${ }^{3}$

Estes estudos empíricos demonstraram, pela primeira vez, a importância de redes formais e informais de inovação, mesmo que a palavra "rede" não fosse utilizada. Tais trabalhos representam, de fato, os pilares básicos sobre os quais, nos últimos 25 anos, vem sendo desenvolvida uma "teoria da inovação".

A ligação dessa idéia com a conceituação do processo inovativo e com as propostas de políticas de inovação ocorre através do Directorate for Science Technology and Industry (DSTI) da OECD. Mais especificamente: através da formação de um grupo ad hoc de assessoramento em Ciência, Tecnologia e Competitividade que contava com François Chesnais (do próprio DSTI), Christopher Freeman, Keith Pavitt (ambos ex-integrantes do DSTI) e Richard Nelson, entre outros. O grupo produziu Technical Change and Economic Policy (OECD, 1980) - sem dúvida o primeiro documento de política de inovação elaborado por um organismo internacional a desafiar as interpretações macroeconômicas tradicionais para a crise dos anos 70 e que enfatizou o papel das novas tecnologias para sua eventual superação: "a difusão da eletrônica para os demais setores industriais e de serviços resultará em uma economia onde a tecnologia influencie a inovação em toda a parte" (OECD, 1980, p. 48).

O caráter sistêmico da inovação já era reconhecido nos documentos de trabalho do grupo:

the 'coupling mechanisms' between the education system, scientific institutions, $R \& D$ facilities, production and markets have been an important aspect of the institutional changes introduced in the successful national innovation systems (FREEMAN, 1982a).
Mais ainda: foi naquele momento (início dos anos 80) que se reconheceu, também nos países avançados, que as decisões e estratégias tecnológicas são dependentes de fatores muito mais amplos - como aqueles relativos aos setores financeiros, sistemas de educação e organização do trabalho (sinalizando já uma definição de "sistema nacional de inovação"). É interessante perceber que - conforme observado por diversos autores latino-americanos e caribenhos, desde os anos 70 -, para entender a dinâmica do desenvolvimento industrial e tecnológico e propor políticas adequadas para sua mobilização, é fundamental considerar e atuar sobre os condicionantes do quadro macroeconômico, político, institucional e financeiro específico de cada país. A percepção fundamental que levou a esta ênfase foi a observação de que esse contexto nos países menos desenvolvidos (PMDs) constitui-se em importante "política implícita", que pode dificultar e até anular as políticas explícitas específicas (HERRERA, 1971). ${ }^{4}$

Mais significativo, porém, é que estes trabalhos - particularmente os de Chris Freeman (1982a, 1982b) - associam essas idéias sobre o processo inovativo ao surgimento do novo paradigma tecnológico proveniente da idéia da evolução do capitalismo em termos de ondas de crescimento e depressão de longo prazo, de que há necessidade de iniciativas governamentais para se dar conta da incerteza e de um pressuposto (certamente polêmico no contexto da OCDE) de que o livre comércio seria desvantajoso para países menos desenvolvidos.

O passo seguinte, de maior impacto, foi a proposta, no Sundquist Report (OECD, 1988), de se adotar uma abordagem integrada para questões sociais, econômicas e tecnológicas com evidentes implicações para a formulação de políticas. No mesmo ano foi publicada a clássica coletânea Technical Change and Economic Theory (DOSI et al., 1988), que introduziu na literatura acadêmica a idéia de "sistemas de inovação". O DSTI implementou o programa TEP (the Technology-Economy Programme) durante o período 1989 - 1992. Esse programa teve o efeito de, pela primeira vez, transplantar para os documentos de políticas da OCDE as novas idéias sobre sistemas de inovação que iam surgindo a partir das pesquisas anteriormente mencionadas. Principalmente no seu documentosíntese final Technology and the Economy: The Key Relationships (OECD, 1992b), foram introduzidos os conceitos fundamentais advindos dos estudos de inovação - formação de redes de cooperação, parcerias estratégicas, spillovers, a importância do conhecimento tácito. Com maior significado de longo prazo na discussão e 
implementação de políticas, foi introduzido o conceito de sistema nacional de inovação. ${ }^{5}$

Essas evoluções tiveram como conseqüência a maior relevância dada aos estudos de políticas da OCDE, às ligações e conexões dentro dos sistemas nacionais de inovação, assim como a imediata ênfase da visão sistêmica nas propostas de políticas inovadoras. Este é um ponto que será discutido em detalhe mais adiante. Aqui deve-se destacar apenas a dupla característica das novas políticas: a inovação passa a ser o mais importante componente das estratégias de desenvolvimento (e não apenas das políticas de C\&T ou das políticas industriais); e as políticas a ela direcionadas passam a ser entendidas como "políticas direcionadas a sistemas de inovação".

O foco em conhecimento, aprendizado e interatividade deu sustentação à idéia de "sistemas de inovação" (LUNDVALL, 1992; 1995; FREEMAN, 1988), destacando

os ambientes nacionais ou locais onde os desenvolvimentos organizacionais e institucionais produzem condições que permitem o crescimento de mecanismos interativos nos quais a inovação e a difusão de tecnologia se baseiam (OECD, 1992a, p. 238).

O "sistema de inovação" é conceituado como um conjunto de instituições distintas que contribuem para o desenvolvimento da capacidade de inovação e aprendizado de um país, região, setor ou localidade - e também o afetam. Constituem-se de elementos e relações que interagem na produção, difusão e uso do conhecimento. A idéia básica do conceito de sistemas de inovação é que o desempenho inovativo depende não apenas do desempenho de empresas e organizações de ensino e pesquisa, mas também de como elas interagem entre si e com vários outros atores, e como as instituições - inclusive as políticas - afetam o desenvolvimento dos sistemas. Entende-se, deste modo, que os processos de inovação que ocorrem no âmbito da empresa são, em geral, gerados e sustentados por suas relações com outras empresas e organizações, ou seja, a inovação consiste em um fenômeno sistêmico e interativo, caracterizado por diferentes tipos de cooperação.

Com relação a esse último ponto, conclui-se que esses sistemas contêm não apenas as organizações diretamente voltadas ao desenvolvimento científico e tecnológico, mas também, e principalmente, todas aquelas que, direta ou indiretamente afetam as estratégias dos agentes. Um corolário de tal entendimento é que, por exemplo, o setor financeiro e as políticas macroeconômicas mais amplas passam também a ser objeto de preocupação e ação dos policy-makers.

\section{A UTILIDADE DO CONCEITO DE SISTEMAS DE INOVAÇÃO}

As razões que explicam porque a abordagem de sistemas de inovação (SI) atraiu tanto interesse como ferramenta que permite compreender e orientar os processos de criação, uso e difusão do conhecimento, ${ }^{6}$ estão relacionadas ao renascimento do interesse em compreender as mudanças técnicas e as trajetórias históricas e nacionais rumo ao desenvolvimento. Foi particularmente relevante o fato de o conceito ter sido criado e desenvolvido em meados dos anos 80 , exatamente quando tomava corpo, e rapidamente se difundia, a tese sobre a aceleração da globalização econômica que, inclusive, foi associada à hipótese de uma certa tendência ao tecnoglobalismo. $\mathrm{O}$ desenvolvimento desta abordagem reforçou o foco no caráter localizado (e nacional) da geração, assimilação e difusão da inovação em oposição à idéia simplista de um suposto tecnoglobalismo. A capacidade inovativa de um país ou região é vista como resultado das relações entre os atores econômicos, políticos e sociais, e reflete condições culturais e institucionais próprias.

Ao se incorporarem e consolidarem os novos modos de compreensão de inovação, privilegia-se a produção baseada na criatividade humana ao invés das trocas comerciais e da acumulação de equipamentos e de outros recursos materiais - e a inovação e o aprendizado passam a ser caracterizados como processos interativos com múltiplas origens. Portanto, é reforçada a relevância das inovações incrementais e radicais e a complementaridade entre elas, assim como entre as inovações organizacionais e técnicas e suas distintas fontes internas e externas à empresa. Esta, por sua vez, é vista como uma organização inserida em ambientes socioeconômicos e políticos que refletem trajetórias específicas. Assim, cada caso deve ser entendido de acordo com suas peculiaridades, sua posição e seu papel nos contextos nacional e internacional, para que se avalie qual deve ser a estratégia mais apropriada a seu desenvolvimento.

Além da compreensão da natureza sistêmica da inovação, destaca-se também a importância da análise das dimensões micro, meso e macroeconômicas, assim como a das características das esferas produtiva, financeira, social, institucional e política. Argumenta-se que, também aqui, o enfoque sistêmico permite considerar o modo de inserção dos diferentes países na economia e na geopolítica mundial.

Outro avanço crucial consolidado na abordagem de SIN refere-se à constatação de que o conceito de inovação não 
se restringe a processos de mudanças radicais na fronteira tecnológica, realizados quase que exclusivamente por grandes empresas através de seus esforços de pesquisa e desenvolvimento (P\&D). São importantes as conseqüências do reconhecimento de que a inovação se estende para além das atividades formais de $\mathrm{P} \& \mathrm{D}$ e inclui novas formas de produzir bens e serviços, que lhe são novos, independentemente do fato de serem novos, ou não, para os seus competidores - domésticos ou estrangeiros. Essa percepção ajuda a evitar diversas distorções, incentivando os policy-makers a adotarem uma perspectiva mais ampla sobre as oportunidades para o aprendizado e a inovação em pequenas e médias empresas (PMEs) e também nas chamadas indústrias tradicionais. As implicações dessas políticas são significativas, particularmente, em relação aos PMDs.

Este tipo de abordagem revela-se de muita utilidade para esses países. Ao invés de ignorar as especificidades dos diferentes contextos e atores locais, os principais blocos do enfoque em sistemas de inovação exigem que elas sejam captadas e analisadas. A contextualização na análise do processo de aprendizagem e capacitação tem particular importância para países e regiões menos desenvolvidos. Aqui reiteramos que, na discussão sobre geração e uso de conhecimentos de relevância para fins econômicos, o contexto importa e a geopolítica ainda mais. A ênfase em tratar a inovação como um processo cumulativo e específico ao contexto determinado permite desmistificar, por exemplo, idéias simplistas sobre as possibilidades de gerar, adquirir e difundir tecnologias em países menos desenvolvidos. Tal ênfase torna claro que a aquisição de tecnologia no exterior não substitui os esforços locais. Ao contrário, é necessário muito conhecimento para poder interpretar a informação, selecionar, comprar (ou copiar), transformar e internalizar a tecnologia importada.

Outro aspecto essencial para todos os países, especialmente os menos desenvolvidos, é o papel central dado à inovação para a competitividade dinâmica e sustentável (COUTINHO; FERRAZ, 1994). Esta contrasta com a usual prioridade dada à exploração das vantagens competitivas tradicionais (como baixos custos de mão-de-obra e de exploração de recursos naturais sem uma perspectiva de longo prazo e manipulação da taxa de câmbio), as quais Fajnzylber (1988) chamou de "espúrias". Este é mais um exemplo das coerências identificadas entre a abordagem utilizada em sistemas de inovação e o pensamento latinoamericano sobre desenvolvimento. Explicitar essas conexões torna-se um tema relevante para este texto, tendo em vista as implicações e propostas de políticas delas decorrentes.

\section{CONEXÕES ENTRE O ENFOQUE EM SISTEMAS DE INOVAÇÃO E O PENSAMENTO LATINO- AMERICANO SOBRE DESENVOLVIMENTO}

Inicialmente deve ser ressaltado o fato de que os fundamentos de ambas as escolas coincidem com a tradição de abordagem da realidade econômica - cujo foco principal é a produção ao invés da troca, como na visão clássica dos fisiocratas (REINERT; REINERT, 2003). Essa tradição, cujas raízes podem ser encontradas na Itália renascentista (SERRA, 1616), sugere que a riqueza se origina de fontes imateriais: fundamentalmente, da criatividade (conhecimento) e que a acumulação de ativos ocorre por meio da incorporação de novas tecnologias que alteram o estoque do conhecimento (inovação).

É a partir da ênfase inicial no conhecimento e nos retornos crescentes a ele associados que podem ser descritos os mecanismos positivos de retro-alimentação na economia, que levam a ciclos virtuosos de desenvolvimento num sistema nacional. A idéia da especificidade nacional presente nos trabalhos renascentistas é característica também das visões cepalina e neo-schumpeteriana - especialmente a partir das conexões com os trabalhos da escola alemã, em particular em List (1856) que também já enfatizava a percepção sistêmica. ${ }^{7}$

Portanto, para ambas as visões, os processos de desenvolvimento econômico são caracterizados por profundas mudanças estruturais na economia, a partir de descontinuidades tecnológicas que afetam e também são afetadas pela estrutura produtiva, social, política e institucional de cada nação, sendo que cada uma delas apresenta suas especificidades. Como não é linear e seqüencial, o desenvolvimento é um processo único, que depende de aspectos que envolvem suas especificidades políticas, econômicas, históricas e culturais. Ele ocorre a partir de mudanças estruturais de longo prazo, que geram rupturas com os padrões historicamente estabelecidos. Tanto a teoria, quanto as recomendações de política são altamente dependentes de cada contexto particular. Assim, a produção (e, portanto, a atividade econômica), nas duas visões, está fortemente enraizada na sociedade.

As formulações centrais de Prebisch e dos neo-schumpeterianos convergem, ainda, num ponto normalmente ignorado pela literatura: para a dualização do sistema 
capitalista, para a idéia de que a evolução do sistema produz, por um lado, o desenvolvimento econômico sistêmico e virtuoso e, por outro, o subdesenvolvimento. Embora esse caráter dual seja geralmente associado à escola cepalina, diversos autores (REINERT, 1996; MYRDAL, 1957) enfatizam que os trabalhos de Schumpeter também sugerem a existência de uma distribuição desigual dos ganhos advindos do progresso técnico, que tem raízes tanto internas (conflitos de capital e trabalho para a apropriação de tais ganhos), quanto, principalmente externas. As fontes externas de tal distribuição desigual têm importantes conotações geopolíticas e ocorrem com os países mais avançados concentrando os avanços na fronteira tecnológica - e se especializando na produção e distribuição de bens e serviços mais sofisticados - e os subdesenvolvidos naqueles caracterizados por baixa produtividade e baixo valor agregado. Myrdal, numa concepção claramente estruturalista indica que a outra face dos círculos virtuosos de desenvolvimento eram os círculos viciosos de subdesenvolvimento e os efeitos perversos produzidos na economia mundial.

Daí a visão cepalina que sugeria que a ruptura com um padrão de especialização baseado na produção e exportação de produtos primários com estas características somente poderia ocorrer a partir da incorporação, na região, dos benefícios da segunda revolução industrial. Nesse sentido, a ênfase dada à industrialização como elemento propagador do processo de desenvolvimento da região por autores como Furtado e Presbisch é exatamente a mesma que aquela dada à revolução das novas tecnologias pelos neo-schumpeterianos.

Assim, uma atualização da visão cepalina dos anos 50 (que enfatizava a importância da industrialização na América Latina) encontra-se na visão neo-schumpeteriana - que discute a maneira como mudanças nos paradigmas técnico-econômicos alteram a fronteira tecnológica e criam novos conjuntos de padrões, práticas e processos produtivos. A resolução dos conflitos entre a emergência do novo paradigma e a estrutura institucional anterior exigiria, em ambas as visões, um papel diferenciado dos Estados nacionais.

Nas duas teorias, o papel do Estado é fundamental para o desenvolvimento. Nega-se a visão neoclássica tradicional - que considera os mercados como se surgissem espontaneamente, caracterizados por uma pretensa auto-organização. Para cepalinos e neo-schumpeterianos, a emergência dos mercados é resultado de intervenções de política estabelecidas tanto do lado da oferta (desenvol- vimento de instituições, quadro de referências legal, estabelecimento de infra-estrutura, etc.), quanto do lado da demanda.

\section{AS NOVAS POLÍTICAS DE INOVAÇ̃̃O}

Conforme foi mostrado em outros textos, mesmo durante o auge do neoliberalismo, os Estados jamais deixaram de intervir fortemente para fomentar o desenvolvimento produtivo e tecnológico e a expansão de setores estratégicos para a dinâmica estrutural, mesmo que estas políticas fossem camufladas por imperativos estratégico-militares (ERBER; CASSIOLATO 1995). Na maior parte dos casos, as novas políticas incluem o desenvolvimento e difusão de novas tecnologias por meio da promoção das atividades de $\mathrm{P} \& \mathrm{D}$ e do estímulo à difusão e cooperação nas áreas de pesquisa genérica de longo prazo. Explicitamente, também visam a promover a consolidação das bases regionais para o desenvolvimento tecnológico, o reforço de malhas de pequenas e médias empresas e o desenvolvimento de atividades consideradas estratégicas para o crescimento econômico doméstico.

Quanto à forma, destaca-se a tendência de as políticas focalizarem conjuntos de atores e seus ambientes, visando potencializar, disseminar e fazer com que seus resultados sejam mais eficazes. Os diferentes contextos, sistemas cognitivos e regulatórios e formas de articulação, de cooperação e de aprendizado interativo entre agentes são reconhecidos como fundamentais na geração, aquisição e difusão de conhecimentos, particularmente aqueles que são tácitos. Paralelamente, assiste-se ao desenvolvimento de instrumentos que abarcam estes atores coletivos, em complementação à tradicional ênfase a atores individuais. Assim, as novas políticas centradas na promoção de sistemas de inovação e nas relações entre empresas e demais atores diferem das políticas baseadas nas antigas visões dicotômicas e lineares da inovação. Por um lado, superase o dilema de fomentar o lado da oferta ou da demanda de tecnologias, como se estas fossem alternativas excludentes, por outro supera-se a visão funcional, pontual e hierarquizada do processo de geração e difusão de conhecimento (ciência, tecnologia, inovação).

Algumas destas políticas têm se concretizado através do estímulo à formação de novas instituições e organizações de natureza coletiva, e da implementação de ações que estimulam as empresas e demais atores locais a interagirem. Além dos projetos de pesquisa e desenvolvimento conjuntos, tais ações têm incluído a formação e capacitação 
de recursos humanos, informação, design, etc. Ressaltase que estas políticas voltadas para a promoção da interatividade de forma alguma substituem as ações de apoio público à infra-estrutura científica e tecnológica. $\mathrm{Na}$ Era do Conhecimento, torna-se ainda mais fundamental o fortalecimento das instituições de ensino e pesquisa, dentro de uma estratégia orquestrada de planejamento de longo prazo. Portanto, as novas políticas, além de reforçarem as instituições científicas e tecnológicas, enfatizam a importância da interação entre diferentes atores, apostando que a geração, aquisição e difusão de conhecimentos constituem, de fato, processos interativos e simultâneos. (LASTRES; CASSIOLATO, 2003).

Alguns países vêm adotando estratégias que visam, explicitamente, a mobilização de sistemas de inovação (CASSIOLATO, 1999). A Suécia, por exemplo, ao perceber a perda de competitividade de sua indústria de commodities de papel e celulose, tendo em vista a maior eficiência de competidores brasileiros e tailandeses, resolveu reestruturá-la em meados dos anos 90. Essa mudança estrutural foi realizada a partir da organização de processos cooperativos entre produtores de papel e celulose, produtores de bens de capital para esse segmento centros públicos de pesquisa, empresas locais de software, sob a coordenação conjunta do governo sueco e da confederação da indústria. $\mathrm{O}$ programa visava a aprofundar o sistema de produção e de inovação nesse segmento, de forma a permitir uma especialização em papéis especiais. O resultado líquido foi a mudança do padrão de especialização e a maior agregação de valor no país. No plano institucional, o governo sueco promoveu uma importante mudança, no início da primeira década de 2000 . E o ponto mais significativo dessa mudança foi a criação de uma agência (Vinova) para focalizar as ações de política em sistemas de inovação (EDQUIST, 2003).

Mesmo sem explicitarem essa visão sistêmica, há outros países que, na prática, vêm envolvendo atores e mobilizando elementos similares. No caso dos EUA, exemplos são os projetos do Sematech para a indústria de semicondutores, em meados dos anos 80 e o do Supercar, no início da década de 90 organizado sob a coordenação do US Council for Automotive Research (instituição fundada pela Ford, General Motors e Chrysller), em que o Governo Federal exercia a coordenação da política (através do Departamento de Comércio) e alocava recursos (aproximadamente US\$ 1 bilhão do orçamento do Departamento de Energia). ${ }^{8}$ No Japão, arranjos de cooperação vêm sendo promovidos freqüentemente pelo governo, e o suporte a redes de P\&D tem desempenhado importante papel na política governamental para a área. Estima-se que cerca de 4/5 do orçamento governamental para P\&D sejam alocados a projetos de colaboração, envolvendo várias associações de pesquisa e consórcios industriais e ainda a montagem de centros de pesquisa geridos por grupos de empresas (LASTRES, 1994). Amsden (2004) mostra como neste e nos demais países asiáticos os governos seguem fomentando ativamente a "substituição de importações" de peças e componentes nas indústrias de alta tecnologia por empresas de capital local - o que configura as políticas de estruturação dos novos setores.

As ações de política voltadas para o estímulo de processos de cooperação e interação entre empresas, e entre estas e outras organizações dos sistemas nacionais de inovação, têm obtido resultados significativos. Apesar das dificuldades metodológicas para mensurar processos de cooperação, as evidências disponíveis têm confirmado a sua generalização. De acordo com dados da II European Community Innovation Survey, mais de 30\% das empresas européias responderam dispor de arranjos cooperativos com diferentes parceiros, voltados para a inovação. Nos países nórdicos, esta percentagem é ainda maior do que a média européia, com mais de $60 \%$ das empresas inovadoras declarando utilizar algum tipo de cooperação.

No final da década passada um grupo de trabalho (Focus Group on Innovative Networks) foi estabelecido na OCDE visando, especificamente, à investigação detalhada de tais processos. ${ }^{9}$ Além de examinar os dados das pesquisas de inovação, o grupo realizou uma série de investigações empíricas ${ }^{10}$ em diferentes países, concluindo que as empresas que inovam (geralmente entre $40 \%$ e $80 \%$ das empresas pesquisadas) têm uma forte tendência a colaborar. Os resultados desse esforço coincidem integralmente com as conclusões e proposições sugeridas nos trabalhos iniciais dos anos 80 (FREEMAN, 1983; 1987; LUNDVALL, 1988). Percebe-se ainda uma intensa diferenciação dos padrões de colaboração e interação. Isto é, existem especificidades nacionais nesses padrões. Os sistemas nacionais de inovação apresentam diferenças com relação à extensão, ao motivo e à natureza das colaborações, ligadas em especial à orientação das políticas públicas (macroeconômica e de C,T\&I), aos quadros de referência institucional e a padrões de especialização produtiva. Por fim, aponta-se que os processos de interação e colaboração ocorrem predominantemente entre empresas domésticas. Mesmo que empresas estrangeiras - principal- 
mente clientes e fornecedores de materiais e componentes - também tenham uma função importante nos acordos cooperativos nacionais voltados à inovação, elas cumprem um papel secundário.

Resumindo, principalmente nos países mais avançados, a forma de atuação do Estado no campo das políticas industriais e tecnológicas tem-se alterado, havendo cada vez mais interesse em promover as interações e a cooperação entre os agentes visando a inovação. No próximo item pretende-se apontar como as novas políticas de inovação vêm sendo traduzidas para o contexto dos países em desenvolvimento.

\section{AS NOVAS POLÍTICAS E OS PAÍSES EM DESENVOLVIMENTO: DESAFIOS A SEREM SUPERADOS}

Com a constatação da ineficácia das políticas neoliberais do Consenso de Washington, a premência na formulação de alternativas levou a uma maior percepção da importância da inovação e do conhecimento como importantes determinantes nos processos de desenvolvimento. A partir de então, a ênfase à promoção de sistemas de produção e de inovação, a formatos associativos e a rede, passou a orientar as políticas também na maioria dos países menos desenvolvidos (PMDs). Tais propostas foram encaminhadas, em sua maioria, por agências internacionais, e passaram a influenciar as estratégias implementadas em vários países. Entretanto, ainda persistem profundas diferenças, tanto na compreensão e forma como tais agências as utilizam como na abordagem de sistemas de inovação acima apresentada.

Em primeiro lugar, as propostas formuladas por agências internacionais continuam se valendo de uma visão parcial do processo de globalização, o que sugere a idéia de convergência dos processos de desenvolvimento e padronização do espaço econômico global. Daí a proposição de modelos genéricos de política baseados em benchmarks e best practices, os quais têm como referência o desempenho de grandes empresas multinacionais e as instituições de alguns países desenvolvidos. No entanto, a abordagem de sistemas de inovação nega que tanto as tecnologias, quanto as suas formas de promoção, tendam a se tornar globais não sendo, desse modo, passíveis de generalização. Tal abordagem nega ainda a possibilidade de existência de instituições-padrão passíveis de réplica. O reconhecimento da especificidade de cada sistema local significa que não há uma única fórmula comum a ser aplicada em todos os casos e implica conjuntos específicos de requerimentos que variam no tempo e podem levar a diversos caminhos.

Uma segunda diferença, que é correlata, é a ignorância da influência dos diferentes contextos macroeconômicos e nacionais, que chegam a constituir políticas implícitas com o poder de dificultar e até anular as políticas explícitas específicas. Uma terceira diferença referese ao papel das diversas instâncias governamentais na formulação e implementação de políticas em PMDs. A ênfase nas agências locais e no fortalecimento do capital social local tem sido acompanhada por uma menção explícita à diminuição da importância do poder do governo nacional e o conseqüente aumento do papel das instâncias locais e do chamado terceiro setor (em especial as ONGs). Além do possível questionamento da falta de legitimidade dessas organizações, deve-se recordar que, na abordagem de sistemas de inovação, está explícita a importância da sua dimensão nacional. Assim - e de acordo com a abordagem apresentada aqui - a efetividade das políticas locais será reforçada com sua articulação à estratégia nacional e até supranacional. Mostra-se necessária uma coordenação dos diferentes níveis (desde o local, ao nacional e internacional) e tipos de políticas, assim como agências intervenientes - o que demanda uma forma de ação que só pode ser realizada na instância mais elevada do governo.

Outra diferença de como os sistemas de inovação são vistos pelos organismos internacionais de financiamento refere-se à suposição de que o acesso ao mercado externo traz oportunidades de aprendizado superiores e que, portanto, a política industrial deve priorizar exportações. Como decorrência disso, uma parte significativa das prioridades das políticas de desenvolvimento industrial e tecnológico atualmente em vigor está ainda mais fortemente centrada nas possibilidades de exportação e nas empresas exportadoras. No entanto, torna-se cada vez mais evidente que os produtores locais, que operam em cadeias globais, encontram barreiras significativas para desenvolver capacitação inovativa e que cadeias integradas em âmbito nacional (ou que se estendem aos países vizinhos) proporcionam melhores oportunidades para isso. Schmitz (2005), por exemplo, assinala que os resultados de pesquisas empíricas indicam que as empresas que têm os mercados nacionais ou regionais como alvo investem mais em design e marketing e têm adquirido capacidades que não foram desenvolvidas pelos fabricantes que exportam para a América do Norte ou para a Europa. Assim, ele demonstra que essas empresas deveriam ser "as novas heroínas no 
debate de política industrial". Essas conclusões são consistentes com os resultados da análise de mais 30 sistemas produtivos e inovativos locais realizados pela RedeSist em diferentes estados brasileiros (CASSIOLATO, et al., 2003).

Deve-se notar que esta prática de utilizar novos enfoques como o de sistema de inovação apenas como um rótulo novo em posturas tradicionais vem sofrendo sérias críticas. Como apontado, por exemplo, por Reinert e Reinert (2003, p. 5):

em nossa visão, existe um risco de se implementar a abordagem de sistemas nacionais de inovação como uma fina camada de glacê num sólido bolo neoliberal. ${ }^{11}$

Assim, se é verdade que as propostas de política sugeridas por organizações internacionais passam a dar ênfase a variáveis como conhecimento e inovação, elas continuam a conceber a intervenção do Estado a partir das necessidades de compensar ou corrigir as imperfeições do mercado, e de criar instituições adequadas ao seu bom funcionamento - quase sempre aquelas que se referem especificamente à evolução histórica dos países anglosaxões. A política tecnológica da maioria dos países em desenvolvimento (inclusive o Brasil) parte do pressuposto de que o papel do Estado é fundamentalmente auxiliar, deixando ao mercado a definição dos programas empresariais. Tal política é assim parte de uma "agenda reformista" que aceita a intervenção para "corrigir falhas de mercado", supostamente relativas ao tempo de reação dos empresários aos estímulos trazidos pela concorrência advinda da desregulamentação e abertura e a carências do mercado de capitais.

E, principalmente, as políticas continuam a ser "horizontais" e voltadas ou à entidade empresarial isoladamente (por meio da concessão de benefícios fiscais e creditícios) ou à relação universidade-empresa. Ora, como sugere a literatura, mecanismos de estímulo (fiscal e creditício) à empresa individual são no máximo subsidiários (alguns países, como o Reino Unido simplesmente não o utilizam) e os processos de colaboração universidade-empresa respondem por uma pequena parcela da cooperação voltada à inovação. Assim, o Brasil continua a ter uma atitude tímida e parcial quanto a essa importante questão.

\section{CONCLUSÕES}

Utilizando uma abordagem histórica para analisar o papel do Estado no âmbito das políticas industrial e tecnológica Freeman (1983) mostra que as mudanças estruturais associ- adas a grandes revoluções tecnológicas têm levado a uma constante redefinição do grau e forma da intervenção pública, ${ }^{12}$ essa redefinição não implica em maior ou menor grau de intervenção, mas sim em diferentes formas de intervenção; a divisão de atribuições entre Estado e setor privado envolve necessariamente complexos fenômenos sociais de aprendizado de agentes e grupos, assim como os conflitos sociais e políticos a eles associados. Lembrando, portanto, que o que muda ao longo do capitalismo é a natureza da intervenção e as maneiras pelas quais ela se apresenta, o autor observa que, acompanhando a diversidade, há três características gerais que merecem ser resgatadas:

- a experiência histórica de ciclos e mudanças nos processos de concorrência internacional tem demonstrado a crescente importância da orientação do Estado, tanto na educação básica e nos demais níveis como na pesquisa;

- a necessidade de envolvimento do Estado para administrar os problemas de instabilidade da moeda, taxas de câmbio, taxas de juros, confiança no sistema bancário e de crédito;

- as mudanças de paradigma tecnológico trazem novas necessidades por regulamentação e desregulamentação que invariavelmente demandam a intervenção do Estado.

A perspectiva histórica mostra que cabem ao Estado papéis da maior importância, seja como agente estruturante das novas forças produtivas, seja como propulsor e orientador da sua difusão através da economia e sociedade. Constituem um elemento importante dessa visão as coalizões estratégicas entre o Estado e os segmentos da sociedade civil, com objetivos e compromissos recíprocos definidos de forma explícita. Por outro lado, a ênfase à preservação e promoção da diversidade e a importância atribuída à cooperação conferem ao Estado importante papel de coordenador das necessárias políticas descentralizadas - isso tudo dentro de um projeto de desenvolvimento de longo prazo para o país.

Há claras proposições de política que emanam da abordagem de sistemas de inovação que poderiam inspirar a política brasileira. Inicialmente, é necessária uma transformação do sistema nacional de inovação, no sentido de incorporar os sistemas baseados nas novas tecnologias. Em segundo lugar, deve-se buscar o apoio substantivo a mudanças na estrutura produtiva, isto é, à transição de trajetórias nas diferentes atividades econômicas permitidas pelas mesmas novas tecnologias.

Em ambos os casos, a abordagem enfatizada neste texto sugere a inoperância das chamadas "políticas neutras". 
Estas, que têm sido sugeridas e implementadas a partir das recomendações das agências internacionais, podem ser tão irrelevantes que terão efeito nulo. Esse é, por exemplo, o caso dos incentivos fiscais generalizados voltados a P\&D. Podem até gerar efeitos perversos ao acirrarem as desigualdades, como é o caso das políticas que tentam buscar a modernização rápida através da importação pura e simples de equipamentos. Cabe ao Estado o caráter pró-ativo voltado para coordenação e indução dos processos de transformação produtiva, visando internalizar os benefícios potenciais proporcionados por tecnologias de um novo paradigma tecnológico.

Por fim, a política de sistemas de inovação deve apresentar claramente um viés pró-emprego. Assim, o governo deveria estimular com clareza sistemas produtivos e inovativos caracterizados pela alta importância de inovações de produto dado que eles tendem a apresentar um efeito líquido positivo de geração de novos empregos. Por outro lado, sistemas produtivos e inovativos na qual inovações de processo são mais relevantes deveriam combinar as necessárias políticas de inovação a outras que amortecessem a queda no emprego resultante.

\section{NOTAS}

1. Definidas como sucesso comercial: lucratividade e ampliação de fatia de mercado.

2. Inovações que não deram certo, que consumiram muitos recursos sem que se obtivesse sucesso comercial - como foi o caso do couro sintético da Dupont, para o qual foram investidos $500 \mathrm{mi}$ lhões de dólares.

3. No mesmo período, uma série de trabalhos capitaneados por Nathan Rosenberg na Universidade de Stanford também propiciou um melhor entendimento do processo inovativo. O ápice destes trabalhos é a produção do chamado chain link model (KLINE; ROSENBERG, 1986) que teve um profundo impacto nos policymakers e na elaboração do Manual de Oslo.

4. Ver também Katz (2005) e Coutinho (2005).

5. "When the outcome of this programme was summed up in Montreal in 1991, the concept, National systems of Innovation, was given a prominent place in the conclusions" (LUNDVALL, 1992, p. 5).

6. Veja Lundvall (1992) e Freeman (1995).

7. Para detalhes ver Lastres (1994).

8. Uma dimensão particularmente importante da intervenção norteamericana refere-se ao federalismo do país. Existem 83.000 instituições de política industrial em nível subnacional no país e as instituições financeiras locais desempenham um papel importante no financiamento de atividades de longo prazo (CASSIOLATO; BRITTO, 1997).
9. Ver os resultados das pesquisas do grupo da OCDE em Christensen et al. (1999) e OECD (1999).

10. Utilizou-se a metodologia pioneira desenvolvida pelo grupo da Universidade de Aalborg para um trabalho sobre cooperação na Dinamarca (a pesquisa DISKO). Ver: <www.aalborg.auc.dk>.

11. "We argue that by integrating some Schumpeterian variable to mainstream economics we may not arrive at the root causes of development. We risk applying a thin icing on what is essentially a profoundly neoclassical way of thinking [...] As emphasized in the NIS approach, it is crucial to understand the different national contexts" (REINERT; REINERT, 2003, p. 60).

12. Por exemplo, a institucionalização de organismos de defesa da concorrência não pode ser compreendida sem se levar em consideração as profundas mudanças associadas ao surgimento de grandes empresas e à concorrência oligopolista do início do século XX, que tornaram ultrapassadas a concorrência atomizada entre pequenas empresas típicas do início do século XIX.

\section{REFERÊNCIAS BIBLIOGRÁFICAS}

AMSDEN, A. La sustitución de importaciones en las industrias de alta tecnología: Prebisch renace en Asia. Revista de la Cepal, n. 82 , p. 74-94, abr. 2004.

AROCENA. R.; SUTZ. J. Knowledge innovation and learning: systems and policies in the north and in the south. In: CASSIOLATO, J.E.; LASTRES, H.M.M.; MACIEL, M.L. (Ed.). Systems of innovation and development: evidence from Brazil. Cheltenham: Edward Elgar, 2003.

BASRI, E. Inter-firm technological collaboration in Australia in an international context: implications for innovation performance and public policy. Innovative networks: collaboration in national innovation systems. Paris: OECD Proceedings, 2001.

BRISOLLA, S. et al. As relações universidade-empresa-governo: um estudo sobre a Universidade Estadual de Campinas. Educação \& Sociedade, ano XVIII, n. 61, dez. 1997.

CASSIOLATO, J.E. The role of user-producer relations in innovation and diffusion of new technologies: lessons from Brazil. 1992. Tese (Doutorado) - Universidade de Sussex, Inglaterra, 1992.

CASSIOLATO, J.E.; LASTRES, H.M.M. Tecnoglobalismo e o papel dos esforços de P\&D\&I das multinacionais no Brasil. Parcerias Estratégicas, n. 22, 2005. No prelo.

Sistemas de inovação: políticas e perspectivas. Parcerias Estratégicas, n. 17, p. 5-30, 2000.

CASSIOLATO, J.E.; LASTRES, H.M.M.; MACIEL, M.L. (Ed.). Systems of innovation and development: evidence from Brazil. Cheltenham: Edward Elgar, 2003.

CASSIOLATO, J.E.; RAPINI, M. University-industry interactions in developing countries: na investigation based on Brazilian data. In: CONFERÊNCIA GLOBELICS, 2., out. 2004, Pequim-China: 2004

CASSIOLATO, J.E. et al. A relação universidade e instituições de pesquisa com o setor industrial: uma análise de seus condicionantes. Rio de Janeiro: IE/UFRJ, 1996. 
COUTINHO, L. Regimes macroeconômicos e estratégias de negócios: uma política industrial alternativa para o Brasil no século XXI. In LASTRES, H.M.M., CASSIOLATO, J., ARROIO, A. (Ed.). Conhecimento, sistemas de inovação e desenvolvimento. Rio de Janeiro: Ed. da UFRJ e Contraponto, 2005.

COUTINHO, L.; FERRAZ, J.C. Estudo da competitividade da indústria brasileira. Síntese final. Campinas: FUCAMP, Universidade Estadual de Campinas, São Paulo: Papirus, 1994.

CHRISTENSEN, J.L.; ROGACZEWSKA, A.P.; VINDING, A.L. Synthesis Report of the focus Group on innovative firms and networks. Paris: OCDE, 1999.

DOSI, G. The contribution of economic theory to the understanding of a knowledge-based economy. In: OECD Employment and growth in the knowledge-based economy. Paris: 1996.

EDQUIST, C. (Ed.). Systems of innovation: technologies, institutions and organizations. London: Pinter, 1997.

FAJNZYLBER, F. Competitividad internacional: evolución y lecciones. Revista de la CEPAL, n. 36, dic. 1988.

Industrialización e internacionalización en la América Latina. México Fondo de Cultura Económico, 1980.

FIORI, J. L. O poder americano. Petrópolis, RJ: Vozes, 2004.

FREEMAN, C. The national system of innovation in historical perspective. Cambridge Journal of Economics, v. 19, n. 1, p. 5-24, 1995 .

Technological infrastructure and international competitiveness. Paris: OECD, August 1982a. Mimeo.

Technological infrastructure and international competitiveness. Paris: OECD, August 1982b. (Texto submetido ao grupo ad hoc em ciência, tecnologia e competitividade da OCDE).

FREEMAN, C.; PEREZ, C. Structural crises of adjustment: business cycles and investment behaviour. In: DOSI, G. et al (Ed.). Technical change and economic theory. London: Pinter Publishers, 1988. p. 38-66.

FURTADO, C. O capitalismo global. São Paulo: Paz e Terra, 1998. Terra, 1992

Brasil: a construção interrompida. São Paulo: Paz e

HERRERA, A. Los determinantes sociales de la política científica en América Latina. Política científica explícita y política científica implícita. REDES, v. 2, n. 5, p. 117-131, dic. 1971.

KATZ, J. Structural reform and technological behaviour. The sources and nature of technological change in Latin America in the 1990s. ECLA Working Paper, Santiago de Chile, 1999.

KLEVORICK, A.; LEVIN, R.; NELSON, R.; WINTER, S. On the sources and significance of interindustry differences in technological opportunities. Research Policy, v. 24, p. 185205,1995

KLINE, S.; ROSENBERG, N. An overview of innovation. In: LANDAU, R.; ROSENBERG, N. (Ed.). The positive sum strategy. Harnessing technology for economic growth. Washington D.C.: National Academy Press, 1986. p. 275-306.
KRISTENSEN, P.S.; MADSEN, T. Foreign and domestic partners on product development in small firms. Working Paper, Aalborg University, 2000.

LASTRES, H.M.M. The Advanced Materials Revolution and the Japanese system of Innovation. London: MacMillan, 1994.

LASTRES, H.M.M.; CASSIOLATO, J.E.; ARROIO, A. (Ed.). Conhecimento, sistemas de inovação e desenvolvimento. Rio de Janeiro: Ed. da UFRJ e Contraponto, 2005.

LASTRES, H.M.M.; CASSIOLATO, J.E. Promoting innovative systems in Brazil: new policies or only new icing on old cakes? In: GLOBELICS CONFERENCE, 2., Beijing. October 2004. Disponível em: <http://www.ie.ufrj.br/globelics/>.

LASTRES, H.M.M.; FERRAZ, J.C. Economia da informação, do conhecimento e do aprendizado. In: LASTRES, H.M.M.; ALBAGLI, S. (Org.). Informação e globalização na era do conhecimento. Rio de Janeiro: Campus, 1999.

LEMOS, C. Inovação na era do conhecimento. In: LASTRES, H.M.M.; ALBAGLI, S. (Org.) Informação e globalização na era do conhecimento. Rio de Janeiro: Campus, 1999.

LIST, F. The National System of Political Economy. Philadelphia: JB Lippincott and Co., 1856.

LUNDVALL, B-Å (Ed.). National innovation systems: towards a theory of innovation and interactive learning. London: Pinter, 1992 .

Innovation as an interactive process: from userproducer interaction to the national system of innovation. In: DOSI, G. et al (Ed.). Technical change and economic theory. London: Pinter Publishers, 1988. p. 349-369.

LUNDVALL, B-Å.; BORRÁS, S. The globalising learning economy: implications for innovation policy. Research Report - TSER Programme, DG XII European Commission. Luxembourg: European Communities, 1998.

MYTELKA, L. Proposição de um banco de fomento a sistemas produtivos locais (cluster bank). In: LASTRES, H.M.M. et al. (Coord.). Interagir para competir: promoção de arranjos produtivos e inovativos no Brasil. Brasília: Sebrae, 2002.

MYRDAL, G. Economic theory and under-developed regions. London: Duckworth, 1957.

MYTELKA, L. A role for innovation networking in the other two-thirds. Futures, July/August 1993.

OECD. Boosting innovation: the cluster approach. Report from the Focus Group on Clusters. Paris: 1999.

. Proposed guidelines for collecting and interpreting innovation data (Oslo Manual). Paris: 1992a. Paris: $1992 \mathrm{~b}$

Technology and the economy: the key relationships.

PEREZ, C. Structural change and the assimilation of new technologies in the economic and social systems. Futures, v. 15, n. 5,1983 . p. $357-375$.

RAPINI. M. S. Interação universidade-indústria no Brasil: uma análise exploratória a partir do diretório de pesquisas do $\mathrm{CNPq}$. 2004. Dissertação (Mestrado) - Universidade Federal do Rio de Janeiro-Instituto de Economia, Rio de Janeiro, 2004. 
REINERT, E. The role of technology in the creation of rich and poor nations: Underdevelopment in a Schumpeterian system. In ALDCROFT, D.; ROSS C. (Ed.). Rich Nations - Poor Nations. The long run perspective. Aldershot, Edward Elgar, 1996.

REINERT, E.; REINERT, S. Innovation systems of the past: modern nation-states in a historical perspective. The role of innovations and of systemic effects in economic thought and policy. In: GLOBELICS CONFERENCE, 1., 2003, Rio de Janeiro. Innovation systems and development strategies for the third millennium. Rio de Janeiro, 2003. Disponível em: $<$ http://www.ie.ufrj.br/globelics/>.

ROTHWELL, R.; et al. Updated - project SAPPHO phase II. Research Policy, v. 3, p. 258-291, 1974.

SANTOS, M. Por uma outra globalização: do pensamento único à consciência universal. Rio de Janeiro: Record, 2001.

SCHMITZ, H. Aglomerações produtivas locais e cadeias de valor: como a organização das relações entre empresas influencia o aprimoramento produtivo. In: LASTRES, H.M.M.:

CASSIOLATO, J.E.; ARROIO, A. (Ed.) Conhecimento, sistemas de inovação e desenvolvimento. Rio de Janeiro: Ed. da UFRJ e Contraponto, 2005.

SERRA, A. Breve trattato delle cause che possono far abbondare li regni d'oro e argento dove non sono miniere. Napoles: Lazzaro Scoriggio, 1613.
TAVARES, M.C.; FIORI, J.L. (Org.). Poder e dinheiro: uma economia política para a globalização. Rio de Janeiro: Vozes, 1997.

José Eduardo Cassiolato: PhD em Desenvolvimento, Industrialização e Política de Ciência e Tecnologia, Professor do Instituto de Economia da UFRJ e Coordenador da Rede de Pesquisa em Sistemas Produtivos e Inovativos Locais (IE/UFRJ) (cassio@ie.ufrj.br).

Helena Maria Martins Lastres: PhD em Desenvolvimento, Industrialização e Política de Ciência e Tecnologia, Pesquisadora Titular do IBICT/MCT, Professora e Coordenadora da Rede de Pesquisa em Sistemas Produtivos e Inovativos Locais - RedeSist do Instituto de Economia da Universidade Federal do Rio de Janeiro (hlastres@redesist.ie.ufrj.br).

Artigo recebido em 21 de fevereiro de 2005. Aprovado em 18 de março de 2005. 